\title{
Poly( $p$-Phenylenediamine) as an Inhibitor for Mild Steel in Hydrochloric Acid Medium
}

\author{
S.S Abd El Rehim, ${ }^{a}$ S.M. Sayyah ${ }^{b}$ and R.E. Azooz ${ }^{b, *}$ \\ ${ }^{a}$ Chemistry Department, Faculty of Science, Ain Shams University, Abbassia, Cairo,Egypt. \\ ${ }^{b}$ Polymer Research Laboratory, Chemistry Department, Faculty of Science, Beni-Suef \\ University, 62514 Beni-Suef, Egypt.
}

Received 7 March 2011; accepted 28 February 2012

\begin{abstract}
The corrosion behavior of mild steel (MS) in $\mathrm{HCl}$ solution containing various concentrations of electropolymerized $\mathrm{P}(\mathrm{p}$-phenylenediamine), $\mathrm{P}(\mathrm{pPD})$, has been investigated using weight loss and potentiodynamic polarization techniques. The data obtained from the two techniques are comparable and showed that the presence of $\mathrm{P}(\mathrm{pPD})$ in the acid solutions suppresses the corrosion rate of MS indicating that these polymers act as corrosion inhibitors (predominantly as anodic inhibitors). The inhibition efficiency (IE\%) of the polymer enhances with increasing their concentrations and decrease with an increase in temperature. The inhibition occurs through adsorption and formation of barrier film on the metal surface which separates the metal from direct contact with the corrosive medium and hence protects the metal against the corrosion. The adsorption followed the Langmuir isotherm. The thermodynamic functions of the adsorption and dissolution processes were evaluated.
\end{abstract}

Keywords: corrosion; inhibition; protection efficiency; mild steel; Langmuir isotherm.

\section{Introduction}

The uniform corrosion is the main problem in using mild steel (MS) in acidic solution. To protect MS from acidic environment corrosion inhibitors or coatings are used.

The most effective factors for the inhibiting effects of organic polymers are: the electronegative atoms (such as, N, S, P, O, etc.), the unsaturated bonds (such as, double bonds or triple bonds, etc.), the plane conjugated systems including all kinds of aromatic cycles, molecular area and molecular weight of the inhibitor molecule [2-10].

\footnotetext{
*Corresponding author. E-mail: re_azooz@yahoo.com
} 
According to the type of inhibitor species (anodic or cathodic) and the nature of metal or alloy, adsorption may be chemical or physical adsorption. In many cases, the efficiency of an organic compound as an inhibitor is due to its adsorption on the metal surface forming a barrier layer which separates the metal from the corrosive media [10].

Some phenylenediamines are used as corrosion inhibitors of MS; pphenylenediamine, pPD, as a monomer was found to be less effective compared with other isomers $\mathrm{o}^{-}$or/and $\mathrm{m}^{-}$phenylenediamine [11]. Also, poly phenylenediamines are used; $\mathrm{P}(\mathrm{oPD})$ with concentration $15 \mathrm{ppm}$ gives inhibition efficiency (IE\%) of 95\% [12], P(pPD) with concentration 50 ppm gives inhibition efficiency (IE\%) of 73\% [13] and P(mPD) after $168 \mathrm{H}$ give 80\% efficiency [14].

In this paper we report the inhibitive action of an electro synthetic $\mathrm{p}(\mathrm{pPD})$ on corrosion of mild steel in $\mathrm{HCl}$ solutions. The inhibition has been evaluated by weight loss and potentiodynamic polarization measurements. It is also the purpose of this work to test the experimental data obtained from the two techniques with Langmuir isotherm at different temperatures, in order to determine the thermodynamic functions for the adsorption process.

\section{Experimental}

\section{Chemicals}

$\mathrm{P}(\mathrm{pPD})$ was obtained by the electropolymerized of reagent grade $\mathrm{p}$ phenylenediamine ( Merck- Darmstadt, Germany) in aqueous acidic $\mathrm{HCl}$ (Riedel-de-Haën, Germany) by cyclic voltammetry technique [12]. Characterization is done by using FTIR- spectroscopy, UV spectroscopy, TGA and element analysis. The proposed structure of this polymer using these tools is represented in Scheme (1). DMF were provided by El-Naser Pharmaceutical Chemical Company (Egypt).

\section{$[\mathrm{NH} \longrightarrow \mathrm{NH} \longrightarrow \mathrm{NHH}-\mathrm{NHCl}]_{\mathrm{n}} 6 \mathrm{H}_{2} \mathrm{O} \cdot \mathrm{SO}_{4}$}

Scheme 1. Structure of $\mathrm{P}(\mathrm{pPD})$.

\section{Methodology}

For the weight loss measurements, rectangular specimens of mild steel (MS) (wt. $\%: 98.5 \% \mathrm{Fe}, 0.33 \% \mathrm{C}, 0.24 \% \mathrm{Si}, 0.52 \% \mathrm{Mn}, 0.04 \% \mathrm{Cr}$ and $0.02 \% \mathrm{~S}$ ) of size 3 $\mathrm{cm} \times 4 \mathrm{~cm} \times 0.2 \mathrm{~cm}$ were used. The working electrode was polished mechanically with silicon carbide (SiC) belts, 200 to 600 grit (Buehler, Ltd.), and $1 \mu \mathrm{m} \alpha$-alumina (Buehler, Ltd.), washed with distilled water, then with acetone, and finally with double distilled water and dried. The weight loss, expressed in $\mathrm{mgcm}^{-2}$, was determined by weighing the cleaned samples before and after immersion in $\mathrm{HCl}$ solution for $1 \mathrm{~h}$. Weight loss was determined in the absence or presence of various concentrations of $\mathrm{P}(\mathrm{pPD})$, which was prepared previously in the same manner as [12]. 
The UV-vis.- spectrum for P(pPD) (at room temperature in the range 200-900 nm using dimethylformamide as a solvent and reference) consists of the following absorption peaks:

$\lambda \max =290$ and 263 for $\pi-\pi^{*}$ transition;

$\lambda \max =312 \mathrm{~nm}$ for polaron- $\pi^{*}$ transition and;

$\lambda \max =440 \mathrm{~nm}$ for $\pi$-polaron transition.

The IR-spectra, show the following bands:

$v_{\text {max }}=3415,3150 \mathrm{~cm}^{-1}$ for $\mathrm{NH}_{2}$ stretching vibration or $\mathrm{OH}$ strong hydrogen bonded group in $\mathrm{H}_{2} \mathrm{O}$ molecules of hydration in polymer;

$v_{\max }=3015 \mathrm{~cm}^{-1}$ for $\mathrm{CH}$ stretching vibration of aromatic amine:

$v_{\max }=1115 \mathrm{~cm}^{-1}$ for $\mathrm{CH}$ bending vibration of quinoid ring;

$v_{\max }=1509 \mathrm{~cm}^{-1}$ for $\mathrm{CN}$ stretching vibration of quinod;

$v_{\max }=1288 \mathrm{~cm}^{-1}$ for $\mathrm{CN}$ stretching vibration of radical cation;

$v_{\max }=1509 \mathrm{~cm}^{-1}$ for $\mathrm{CN}$ stretching vibration benzene ring.

A weighted $0.01 \mathrm{~g}$ of polymer was dissolved in solution (DMF: $\mathrm{H}_{2} \mathrm{O}$ mix $(2: 98$ $\mathrm{v} / \mathrm{v})$ ) to give a stock solution containing $100 \mathrm{ppm}$ of inhibitor.

For polarization measurements, the electrolytic cell was filled with $100 \mathrm{~mL}$ of 1.0 $\mathrm{M} \mathrm{HCl}$ solution. The working electrode (MS), auxiliary electrode (Platinum wire) and the Luggin- prob were introduced into the cell containing the test solution $\left(\mathrm{H}_{2} \mathrm{O} / \mathrm{DMF}(98: 2 \mathrm{v} / \mathrm{v})\right.$ and the polymer with different concentrations. Potentiodynamic polarization measurements were performed using the Potentiostat / Galvanostat Wenking PGS 95 connected with PC computer.

The working electrode is a MS specimen in the form of rod. The rod was weld from one side to a copper wire used for electrical connection. The rod was embedded in a glass tube and epoxy resin was used to stick the sample to the glass tube. This also ensured that a constant cross-section area of $2 \mathrm{~cm}^{2}$ would be exposed to the solution through the experiments. The exposed area was ground by different emery papers in the normal way as described above, washed with distilled water, then with acetone, and again with distilled water, just before insertion in the cell. All the potentials were measured relative to the saturated calomel electrode (SCE). The i-E curves were recorded by computer software (Model ECT). For each run, a freshly prepared solution as well as a cleaned set of electrodes was used. Each run was conducted at constant temperature $\pm 1^{\circ} \mathrm{C}$ with using a circular water thermostat.

$\mathrm{P}(\mathrm{pPD})[12]$ has the structure shown in scheme (1).

\section{Results and discussion}

\section{Weight loss and polarization measurements}

The inhibition (protection) efficiency, IE\%, of P(pPD) was calculated for MS sample in the acid solutions in the presence of different concentrations of $\mathrm{P}(\mathrm{pPD})$ at $303 \mathrm{~K}$ using equation [13]:

$$
I E \%=\left(1-\frac{W}{W^{\circ}}\right) \times 100 \quad \text { Eq. (1) }
$$

where, $\mathrm{W}^{\mathrm{o}}$ and $\mathrm{W}$ are the weight loss of MS sample in the absence and presence of $\mathrm{P}(\mathrm{pPD})$, respectively. The relation between IE\% and the logarithm of the 
concentration of the inhibitor in the three acid solutions at $303 \mathrm{~K}$ is shown in Fig. (1). From the figure, The P(pPD) species seems to function as inhibitor by being adsorbed on the metal surface from the corroding medium.

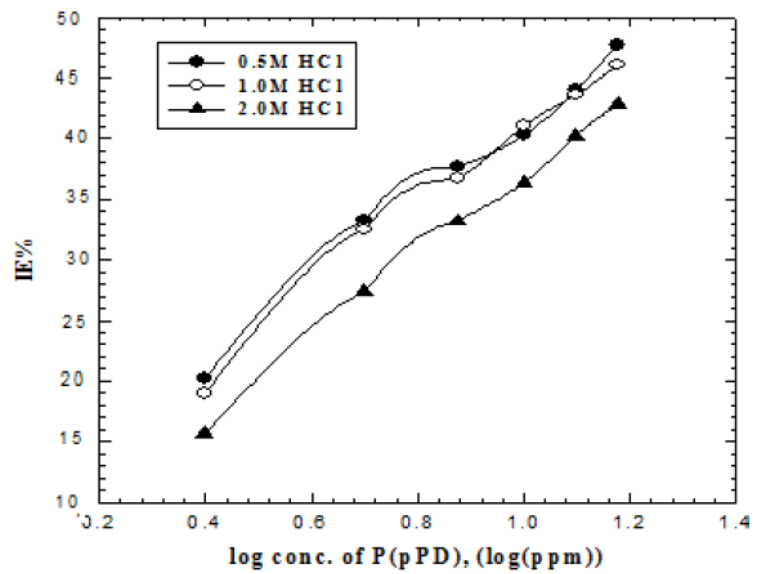

Figure 1. Relation between IE\% and $\log$ of the concentration of $\mathrm{P}(\mathrm{pPD})$ in different $\mathrm{HCl}$ concentrations at $303 \mathrm{~K}$.

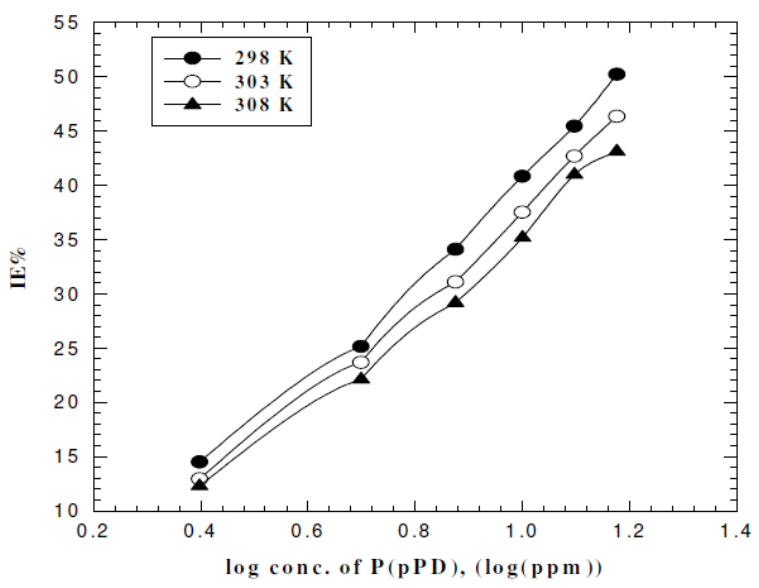

Figure 2. Relation between IE\% and the $\log$ of the concentration of $\mathrm{P}(\mathrm{pPD})$ in $1.0 \mathrm{M}$ $\mathrm{HCl}$ at 298, 303 and $308 \mathrm{~K}$.

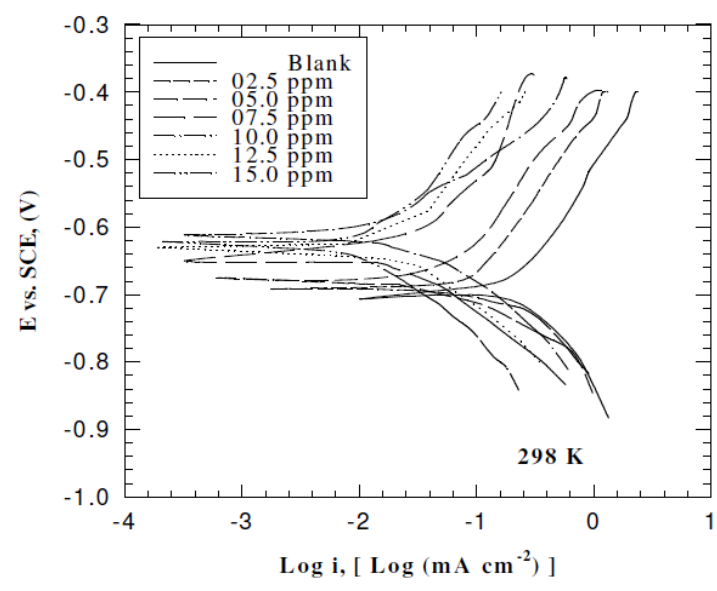

Figure 3. Effect of $\mathrm{P}(\mathrm{pPD})$ concentration on the potentiodynamic polarization curves of MS electrode in $1.0 \mathrm{M} \mathrm{HCl}$ at $298 \mathrm{~K}$. 
To verify the nature of adsorption and the effect of temperature on the corrosion behaviour of MS sample in $1 \mathrm{M} \mathrm{HCl}$ with and without different concentrations of $\mathrm{P}(\mathrm{pPD})$ inhibitor, weight loss studies were undertaken. The selected temperatures tested were 298, 303 and $308 \mathrm{~K}$. The inhibition efficiency, IE\%, under the prevailing conditions was calculated using equation (1) and the dependence of the IE\% on the logarithm of the inhibitor concentration of $\mathrm{P}(\mathrm{pPD})$ at the three tested temperatures was shown in Fig. (2).

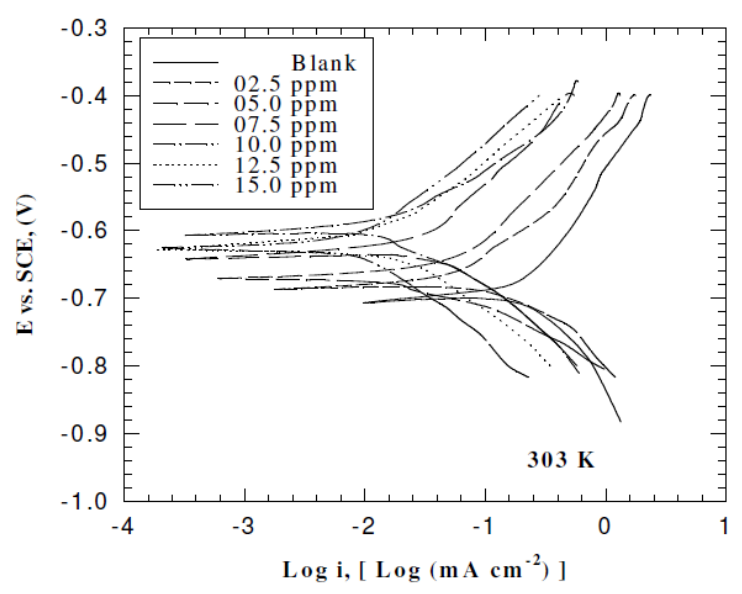

Figure 4. Effect of $\mathrm{P}(\mathrm{pPD})$ concentration on the potentiodynamic polarization curves of MS electrode in $1.0 \mathrm{M} \mathrm{HCl}$ at $303 \mathrm{~K}$.

From Fig. (1) and (2), one can conclude that the inhibition efficiency decrease with increasing the temperature. This can be due to the decrease in the strength of adsorption process at higher temperatures, suggesting that physical adsorption may be the type of adsorption of $\mathrm{P}(\mathrm{pPD})$ compound on MS sample surface. At a given temperature and inhibitor concentration, the inhibition efficiency decreases with increasing $\mathrm{HCl}$ concentration.

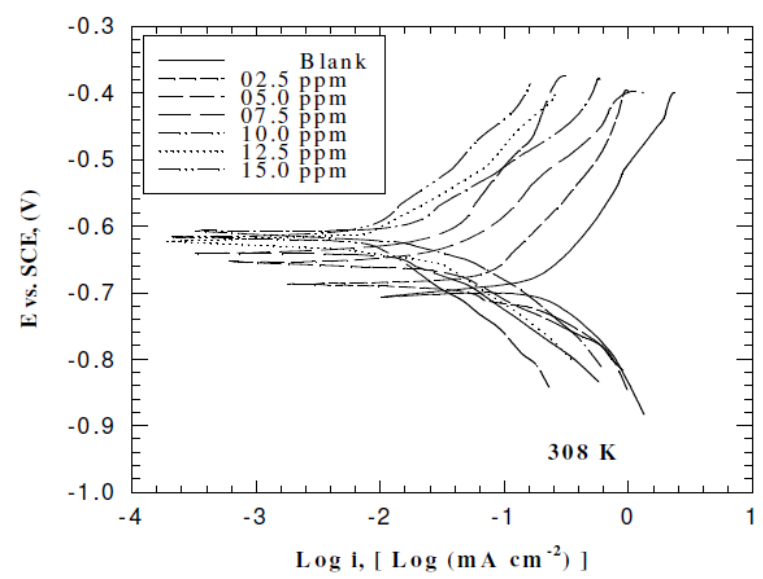

Figure 5. Effect of $\mathrm{P}(\mathrm{pPD})$ concentration on the potentiodynamic polarization curves of MS electrode in $1.0 \mathrm{M} \mathrm{HCl}$ at $308 \mathrm{~K}$.

In order to get more information concerning the type of inhibitor, the nature of inhibition and the influence of the inhibitor on the kinetics of the partial cathodic and anodic reactions, potentiodynamic polarization curves have been conducted. 
This was achieved by investigating the inhibitor concentration and solution temperature dependences of the corrosion current density $\left(i_{\text {corr }}\right)$ and on the corrosion potential (Ecorr), obtained using the Tafel extrapolation method.

Fig. (3), (4) and (5) represent the influence of $\mathrm{P}(\mathrm{pPD})$ concentration on the potentiodynamic cathodic and anodic polarization curves for MS electrode in 1.0 $\mathrm{M} \mathrm{HCl}$ at scan rate of $10 \mathrm{mVs}^{-1}$ and at 298, 303 and $308 \mathrm{~K}$, respectively. The data clearly show that the addition of P(pPD) enhances both the anodic and cathodic overpotentials (but mainly the anodic) and decreases the corrosion current density. These results confirm the suggestion that $\mathrm{P}(\mathrm{pPD})$ functions as inhibitor for the acid corrosion of MS electrode. This inhibitor is classified mainly as anodic inhibitor. In all cases, the polarization curves exhibited Tafel type behavior around the corrosion potential, Ecorr, the electrochemical kinetic parameters associated the polarization curves ( $i_{\text {corr }}, E_{\text {corr }}, \beta_{c}$ and $\beta_{a}$ ) for MS in $1.0 \mathrm{M} \mathrm{HCl}$ in the absence and presence of various concentrations of $\mathrm{P}(\mathrm{pPD})$ and at different temperatures have been simultaneously determined (in the potential rang $\pm 50 \mathrm{mV}$ from $\mathrm{E}_{\text {corr }}$ ) and are given in Tables (1), (2) and (3).

Table 1. Electrochemical kinetic parameters ( $i_{\text {corr }}, E_{\text {corr }}, \beta_{c}$ and $\beta_{a}$ ) and inhibition efficiency (IE\%) obtained from polarization curves of MS electrode in $1.0 \mathrm{M} \mathrm{HCl}$ at $298 \mathrm{~K}$.

\begin{tabular}{|c|c|c|c|c|c|}
\hline $\mathrm{P}(\mathrm{pPD})$ conc. $(\mathrm{ppm})$ & $\begin{array}{c}\mathrm{i}_{\text {corr }} \\
\left.(\mathrm{mA} \mathrm{cm})^{-2}\right)\end{array}$ & $\begin{array}{c}-\mathrm{E}_{\text {corr }} \\
(\mathrm{mV})\end{array}$ & $\begin{array}{c}\beta_{\mathrm{c}} \\
\left(\mathrm{mV} \mathrm{dec}^{-1}\right)\end{array}$ & $\begin{array}{c}\mathrm{B}_{\mathrm{a}} \\
\left(\mathrm{mV} \mathrm{dec}^{-1}\right)\end{array}$ & $\mathrm{IE} \%$ \\
\hline Blank & 400 & 692 & 1.36 & 0.300 & -- \\
\hline 2.5 & 332 & 675 & 0.220 & 1.00 & 17.00 \\
\hline 5.0 & 296 & 650 & 0.400 & 0.907 & 26.00 \\
\hline 7.5 & 253.6 & 634 & 0.140 & 0.778 & 36.60 \\
\hline 10.0 & 206 & 312 & 0.100 & 0.510 & 48.50 \\
\hline 12.5 & 200 & 321 & 0.111 & 0.612 & 50.00 \\
\hline 15.0 & 190 & 316 & 0.105 & 0.614 & 52.50 \\
\hline
\end{tabular}

Table 2. Electrochemical kinetic parameters ( $i_{\text {corr }}, E_{\text {corr }}, \beta_{c}$ and $\beta_{a}$ ) and inhibition efficiency (IE\%) obtained from polarization curves of MS electrode in $1.0 \mathrm{M} \mathrm{HCl}$ at $303 \mathrm{~K}$.

\begin{tabular}{|c|c|c|c|c|c|}
\hline $\mathrm{P}(\mathrm{pPD})$ conc. $(\mathrm{ppm})$ & $\begin{array}{c}\mathrm{i}_{\text {corr }} \\
\left(\mathrm{mA} \mathrm{cm}^{-2}\right)\end{array}$ & $\begin{array}{c}-\mathrm{E}_{\text {corr }} \\
(\mathrm{mV})\end{array}$ & $\begin{array}{c}\beta_{\mathrm{c}} \\
\left(\mathrm{mV} \mathrm{dec}^{-1}\right)\end{array}$ & $\begin{array}{c}\mathrm{B}_{\mathrm{a}} \\
\left(\mathrm{mV} \mathrm{dec}^{-1}\right)\end{array}$ & IE\% \\
\hline Blank & 473.2 & 708 & 1.43 & 0.306 & -- \\
\hline 2.5 & 410 & 672 & 0.226 & 1.00 & 13.35 \\
\hline 5.0 & 356 & 652 & 0.407 & 0.907 & 24.77 \\
\hline 7.5 & 325 & 641 & 0.144 & 0.778 & 31.32 \\
\hline 10.0 & 271 & 632 & 0.104 & 0.510 & 42.74 \\
\hline 12.5 & 260 & 612 & 0.112 & 0.612 & 45.05 \\
\hline 15.0 & 250 & 610 & 0.110 & 0.619 & 47.17 \\
\hline
\end{tabular}


Table 3. Electrochemical kinetic parameters ( $i_{\text {corr }}, E_{\text {corr }}, \beta_{c}$ and $\beta_{a}$ ) and inhibition efficiency (IE\%) obtained from polarization curves of $\mathrm{MS}$ electrode in $1.0 \mathrm{M} \mathrm{HCl}$ at $308 \mathrm{~K}$.

\begin{tabular}{|c|c|c|c|c|c|}
\hline $\mathrm{P}(\mathrm{pPD})$ conc. $(\mathrm{ppm})$ & $\begin{array}{c}\mathrm{i}_{\text {corr }} \\
\left.(\mathrm{mA} \mathrm{cm})^{-2}\right)\end{array}$ & $\begin{array}{c}-\mathrm{E}_{\text {corr }} \\
(\mathrm{mV})\end{array}$ & $\begin{array}{c}\beta_{\mathrm{c}} \\
\left(\mathrm{mV} \mathrm{dec}^{-1}\right)\end{array}$ & $\begin{array}{c}\mathrm{B}_{\mathrm{a}} \\
\left(\mathrm{mV} \mathrm{dec}^{-1}\right)\end{array}$ & $\mathrm{IE} \%$ \\
\hline Blank & 500 & 680 & 1.48 & 0.309 & -- \\
\hline 2.5 & 436 & 653 & 0.201 & 1.000 & 12.80 \\
\hline 5.0 & 390 & 641 & 0.401 & 0.901 & 22.00 \\
\hline 7.5 & 360 & 623 & 0.103 & 0.786 & $28 . .00$ \\
\hline 10.0 & 300 & 607 & 0.109 & 0.519 & 40.00 \\
\hline 12.5 & 290 & 616 & 0.119 & 0.619 & 42.00 \\
\hline 15.0 & 285 & 614 & 0.112 & 0.611 & 43.00 \\
\hline
\end{tabular}

Since the corrosion rate (CR) is directly related to the corrosion current density [14], the inhibition efficiency, IE\%, at different inhibitor concentrations and solution temperatures was calculated from equation [15]:

$$
I E \%=\left[1-\frac{i_{\text {corr }}}{i_{\text {corr }}^{o}}\right] \times 100 \quad \text { Eq. (2) }
$$

where, $\mathrm{i}^{\mathrm{o}}$ corr and $\mathrm{i}_{\text {corr }}$ are the corrosion current density for uninhibited and inhibited solutions, respectively. The calculated values of IE\% are given in Tables (1), (2) and (3). The relation between IE\% versus log P(pPD) concentration at the three tested temperature is shown in Fig. (6). According to these data, it is observed that the inhibition efficiency of $\mathrm{P}(\mathrm{pPD})$ increases with increasing its concentration but decreases with temperature. It is clear that the weight loss and potentiodynamic polarization techniques gave the same trends of inhibition of $\mathrm{P}(\mathrm{pPD})$ and produced nearly the same values of IE\%.

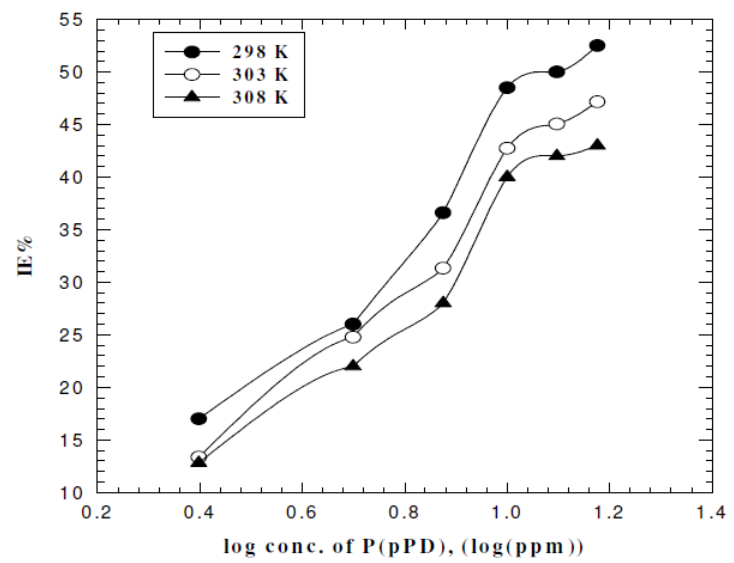

Figure 6. Relation between IE\% and $\log$ of the concentration of $\mathrm{P}(\mathrm{pPD})$ in $1.0 \mathrm{M} \mathrm{HCl}$ at 298,303 and $308 \mathrm{~K}$ for potentiodynamic technique.

\section{Thermodynamic Activation Functions of the Corrosion Process}

More information concerning the adsorption mechanism can be gained by the thermodynamic function for the $\mathrm{MS}$ corrosion in $\mathrm{HCl}$ solution with and without 
different concentrations of $\mathrm{P}(\mathrm{pPD})$. These functions were obtained by applying the Arrhenius equation [16]:

$$
\log (C R)=-\frac{E_{a}^{o}}{2.303 R T}+A \quad \text { Eq. (3) }
$$

where, $\mathrm{E}_{\mathrm{a}}^{\mathrm{o}}$ is the apparent activation energy, $\mathrm{A}$ is the pre-exponential factor, $\mathrm{T}$ is the temperature and $\mathrm{R}$ is the ideal gas constant. An alternative form of Arrhenius equation, [16], is the transition state (Eyring) equation [16]:

$$
C R=\frac{R T}{N h} \exp \left(\frac{\Delta S^{o}}{R}\right) \exp \left(-\frac{\Delta H^{o}}{R T}\right) \quad \text { Eq. (4) }
$$

where, $\mathrm{h}$ is the Planck's constant, $\mathrm{N}$ is the Avogadro's number, $\Delta \mathrm{S}^{\mathrm{o}}$ and $\Delta \mathrm{H}^{\mathrm{o}}$ are respectively the entropy and the enthalpy of activation.
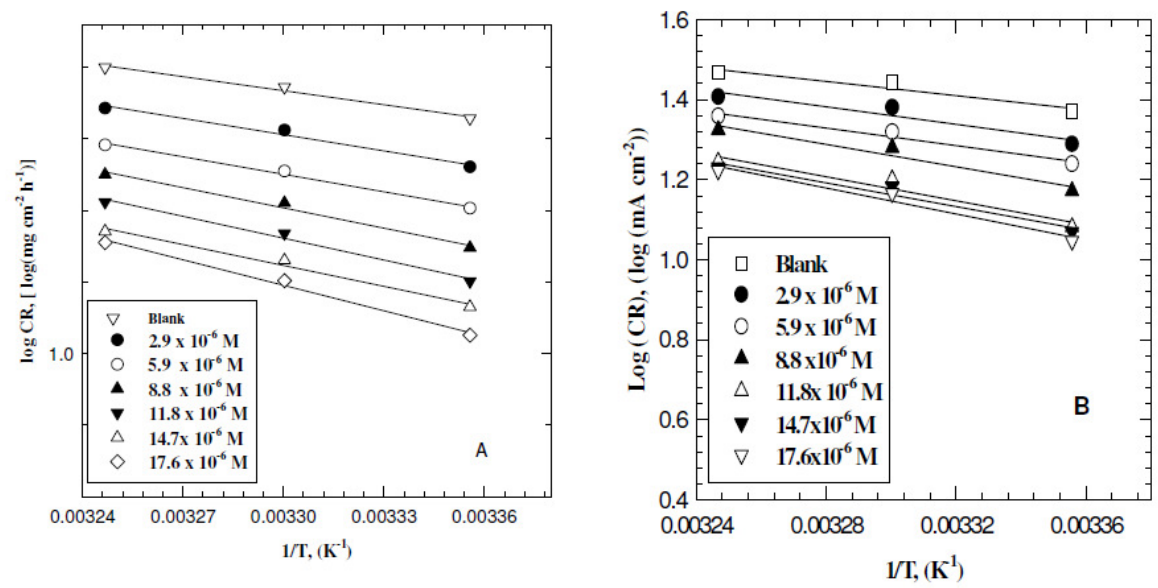

Figure 7. Arrhenius plot of corrosion rate of $\mathrm{MS}$ in $1.0 \mathrm{M} \mathrm{HCl}$ containing various concentrations of $\mathrm{P}(\mathrm{pPD})$. (A) from weight loss and (B) from polarization measurements.

Plotting the relation between logarithmic of the corrosion rate obtained from weight loss and polarization measurements versus 1/T (Arrhenius equation) for MS electrode in $1.0 \mathrm{M} \mathrm{HCl}$ containing various concentrations of $\mathrm{P}(\mathrm{pPD})$ gave straight lines, as shown in Fig. 7(A) and (B), respectively. The values of apparent activation energy, $\mathrm{E}_{\mathrm{a}}^{\mathrm{O}}$, obtained from the slopes of these lines are given in Table (4).

Plotting the relation $\log (\mathrm{CR} / \mathrm{T})$ versus $(1 / \mathrm{T})$ for $\mathrm{MS}$ in $1.0 \mathrm{M} \mathrm{HCl}$ containing various concentrations of $\mathrm{P}(\mathrm{pPD})$ should give straight lines with slope of $\left(-\Delta \mathrm{H}^{\mathrm{o}} /\right.$ $2.303 \mathrm{R})$ and an intercept of $\left[(\log (\mathrm{R} / \mathrm{Nh}))+\left(\Delta \mathrm{S}^{\mathrm{O}} / 2.303 \mathrm{R}\right)\right]$ (transition state equation).

Fig. 8 (A) and (B)) display the plots of $\log (\mathrm{CR} / \mathrm{T})$ versus $(1 / \mathrm{T})$ from data obtained from weight loss and polarization measurements, respectively. The values of the thermodynamic functions $\Delta \mathrm{H}^{\circ}$ and $\Delta \mathrm{S}^{\circ}$ were obtained and are listed in Table (4).

The data infer that the values of $\mathrm{E}_{\mathrm{a}}^{\mathrm{o}}, \Delta \mathrm{H}^{\mathrm{o}}$ and $\Delta \mathrm{S}^{\mathrm{o}}$ of the dissolution of MS in 1.0 $\mathrm{M} \mathrm{HCl}$ solution in the presence of $\mathrm{P}(\mathrm{pPD})$ are higher than those in the blank acid solution. The activation thermodynamic parameters of the corrosion process 
enhance with increasing the inhibitor concentration, indicating that more energy barrier for the corrosion reaction in the presence of inhibitor is attained [17].

Table 4. Thermodynamic activation functions of $\mathrm{MS}$ dissolution in $1.0 \mathrm{M} \mathrm{HCl}$ in the absence and presence of different concentrations of $\mathrm{P}(\mathrm{pPD})$ obtained from weight loss and polarization data by applying Arrhenius and Transition state plots.

\begin{tabular}{|c|c|c|c|c|c|c|}
\hline \multirow{2}{*}{$\begin{array}{c}\mathrm{P}(\mathrm{pPD}) \\
\text { conc.(M)X10 }\end{array}$} & \multicolumn{3}{|c|}{ Weight loss } & \multicolumn{3}{c|}{ Polarization } \\
\cline { 2 - 7 } & $\begin{array}{c}\left.\mathrm{E}^{\mathrm{o}}{ }_{\mathrm{a}}^{-1}\right) \\
\left(\mathrm{kJ} \mathrm{mol}^{-1}\right)\end{array}$ & $\begin{array}{c}\Delta \mathrm{H}^{\mathrm{o}} \\
\left(\mathrm{kJ} \mathrm{mol}^{-1}\right)\end{array}$ & $\begin{array}{c}\Delta \mathrm{S}^{\mathrm{o}} \\
\left(\mathrm{J} \mathrm{mol}^{-1} \mathrm{~K}^{-1}\right)\end{array}$ & $\begin{array}{c}\mathrm{E}^{\mathrm{o}} \\
\left(\mathrm{kJmol}^{-1}\right)\end{array}$ & $\begin{array}{c}\Delta \mathrm{H}^{\mathrm{o}} \\
\left(\mathrm{kJmol}^{-1}\right)\end{array}$ & $\begin{array}{c}\Delta \mathrm{S}^{\mathrm{o}} \\
\left(\mathrm{J} \mathrm{mol}^{-1} \mathrm{~K}^{-1}\right)\end{array}$ \\
\hline Blank & 12.53 & 11.24 & -182.07 & 17.08 & 14.55 & -187.81 \\
\hline 2.9 & 14.49 & 11.99 & -180.54 & 18.32 & 18.32 & -161.20 \\
\hline 5.9 & 15.55 & 13.04 & -178.05 & 18.55 & 18.55 & -159.28 \\
\hline 8.8 & 18.02 & 15.51 & -170.77 & 24.28 & 24.28 & -142.05 \\
\hline 11.8 & 19.51 & 16.98 & -166.75 & 25.27 & 26.23 & -140.14 \\
\hline 14.7 & 21.06 & 17.19 & -163.11 & 25.89 & 26.77 & -138.22 \\
\hline 17.6 & 22.73 & 20.20 & -157.37 & 28.47 & 28.47 & -129.22 \\
\hline
\end{tabular}
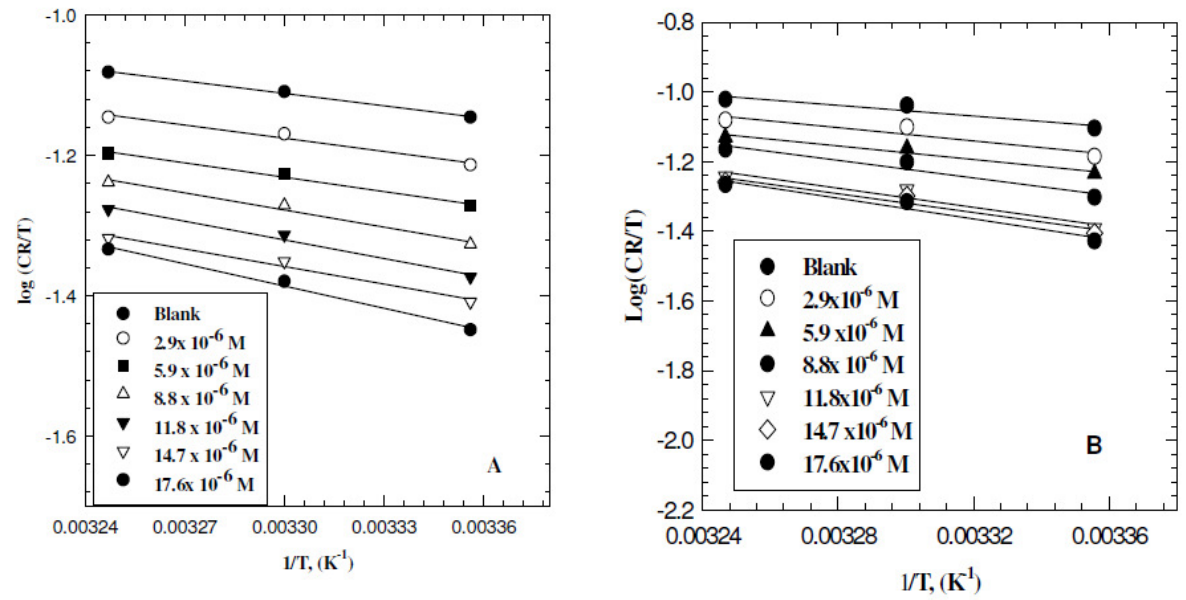

Figure 8. Transition state plot of corrosion rate of $\mathrm{MS}$ in $1.0 \mathrm{M} \mathrm{HCl}$ containing various concentrations of $\mathrm{P}(\mathrm{pPD})$. (A) From weight loss and (B) from polarization measurements.

\section{Adsorption Isotherms and Thermodynamic Functions of Adsorption Process}

Langmuir isotherm has been tested with the experimental data obtained from both weight loss and polarization measurements for MS electrode in $1.0 \mathrm{M} \mathrm{HCl}$ in the presence of different concentrations of $\mathrm{P}(\mathrm{pPD})$ and temperatures.

In all cases, it is observed that the linear regression between $C_{i n h} / \theta$ and $C_{i n h}$, calculated by the computer, and the slope and the linear correlation coefficient $\left(\mathrm{r}^{2}\right)$ are close to unity, as shown in Fig. (9) and (10), respectively; the correlation coefficient $r^{2}$ is higher than 0.99 [20], reflecting adsorption of $\mathrm{P}(\mathrm{pPD})$ species on the electrode surface and applicability of Langmuir isotherm model (c.f. Table (5)). 


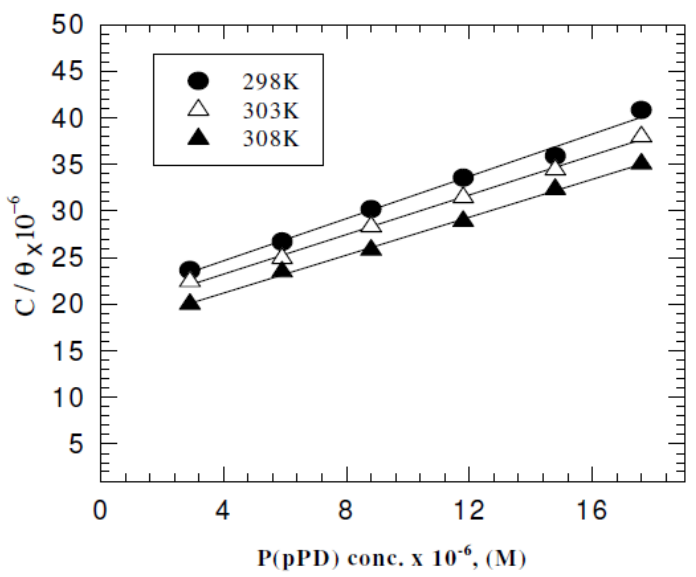

Figure 9. $\mathrm{C}_{\mathrm{inh}} / \theta$ versus $\mathrm{C}_{\mathrm{inh}}$ for $\mathrm{MS}$ in $1.0 \mathrm{M} \mathrm{HCl}$ data obtained from weight loss technique.

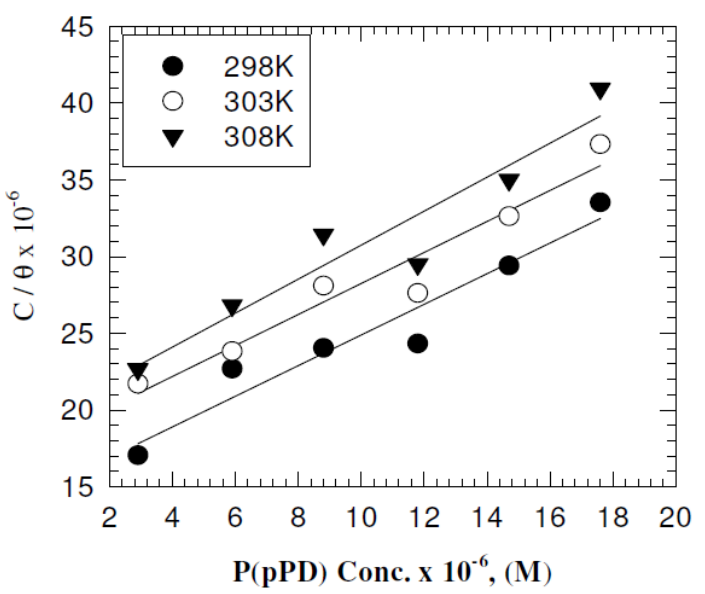

Figure 10. $\mathrm{C}_{\mathrm{inh}} / \theta$ versus $\mathrm{C}_{\mathrm{inh}}$ for $\mathrm{MS}$ in $1.0 \mathrm{M} \mathrm{HCl}$ data obtained from polarization technique.

The adsorption isotherm relationship of Langmuir is represented using the following equation [21]:

$$
\frac{\theta}{1-\theta}=K_{a d s} C_{i n h}
$$

where, $\mathrm{K}_{\mathrm{ads}}$ is the adsorption-desorption equilibrium constant.

Table 5. Data obtained from Fig. (9) and (10).

\begin{tabular}{|c|c|c|c|c|c|c|}
\hline Temp.(K) & $298 \mathrm{~K}$ & $303 \mathrm{~K}$ & $308 \mathrm{~K}$ & $298 \mathrm{~K}$ & $303 \mathrm{~K}$ & $308 \mathrm{~K}$ \\
\hline Slope & 1.31 & 1.05 & 1.02 & 0.99 & 1.01 & 1.11 \\
\hline $\mathrm{r}^{2}$ & 0.991 & 0.997 & 0.998 & 0.995 & 0.996 & 0.991 \\
\hline
\end{tabular}




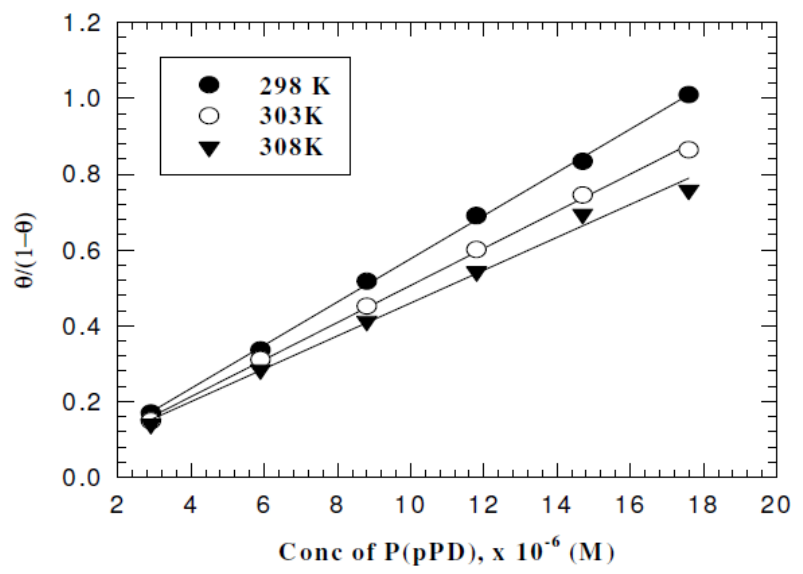

Figure 11. Langmuir isotherm for $\mathrm{MS}$ in $1.0 \mathrm{M} \mathrm{HCl}$ in the presence of different concentrations of $\mathrm{P}(\mathrm{pPD})$ and temperatures. Data from weight loss technique.

However, the relation between of $(\theta / 1-\theta)$ against $C_{\text {inh }}$ gave straight lines, as shown in Fig. (11) and (12). These results show that the fitting of corrosion data is in agreement with Langmuir's isotherm [21] and confirm the assumption that the action of the inhibitor is due to its adsorption at the metal/solution interface. The equilibrium adsorption constant, $\mathrm{K}_{\mathrm{ads}}$, for the adsorption of the inhibitor at MS electrode surface at $\mathrm{T}=298,303$ and $308 \mathrm{~K}$ were obtained from the slopes of these straight lines. The free energies of the inhibitor adsorption, $\Delta \mathrm{G}^{\mathrm{o}}$ ads, were calculated from the equation [22]:

$$
K_{a d s}=\frac{1}{55.5} \exp \frac{-\Delta G_{a d s}^{o}}{R T} \quad \text { Eq.(6) }
$$

where, 55.5 is the molar concentration of water.

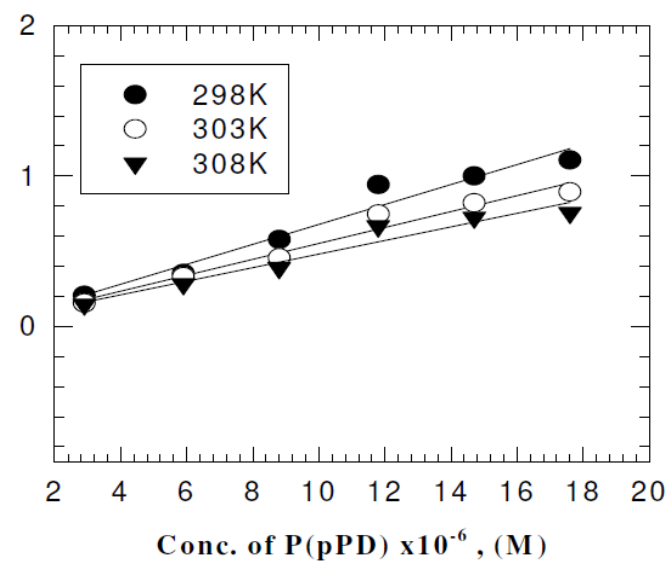

Figure 12. Langmuir isotherm for $\mathrm{MS}$ in $1.0 \mathrm{M} \mathrm{HCl}$ in the presence of different concentrations of $\mathrm{P}(\mathrm{pPD})$ and temperatures. Data from polarization technique. 
Table 6. Thermodynamic parameters of adsorption of $\mathrm{P}(\mathrm{pPD})$ on MS electrode surface in $1.0 \mathrm{M} \mathrm{HCl}$ solution. Data from weight loss technique.

\begin{tabular}{|c|c|c|c|c|}
\hline Temp , (K) & $\mathrm{K}_{\mathrm{ads}} \times 10^{-6}$ & 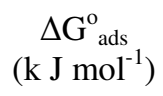 & $\begin{array}{c}\Delta \mathrm{H}_{\text {ads }}^{\mathrm{o}} \\
\left(\mathrm{k} \mathrm{J} \mathrm{mol}^{-1}\right)\end{array}$ & $\begin{array}{c}\Delta \mathrm{S}^{\mathrm{o}}{ }_{\mathrm{ads}}^{-1} \\
\left(\mathrm{~J} \mathrm{~mol}^{-1} \mathrm{~K}^{-1}\right)\end{array}$ \\
\hline 298 & 0.056 & -37.04 & \multirow{3}{*}{-46.41} & \multirow{3}{*}{-143.97} \\
\hline 303 & 0.049 & -37.32 & & \\
\hline 308 & 0.043 & -37.60 & & \\
\hline
\end{tabular}

The integrated version of the Van Hoff equation [22] is:

$$
\ln K_{a d s}=\frac{-\Delta H_{a d s}^{o}}{R T}+\text { constant Eq. (7) }
$$

The calculated values of $\mathrm{K}_{\mathrm{ads}}$ using data obtained from weight loss and polarization measurements are given in Tables (6) and (7), respectively. It is clear that the values of $\mathrm{K}_{\mathrm{ads}}$ are relatively small and decrease with rise of temperature. This behavior indicates that this inhibitor is physically adsorbed on the metal surface and the strength of adsorption decreases with temperature. Moreover, it is seen that there is a good agreement between the values of $\mathrm{K}_{\mathrm{ads}}$ obtained from the two methods used. The average thermodynamic functions $\left(\Delta \mathrm{H}^{\mathrm{o}}\right.$ ads and $\Delta \mathrm{S}^{\mathrm{o}}$ ads $)$ for $\mathrm{P}(\mathrm{pPD})$ adsorption on metal surface were calculated using equations (7) and (8), respectively, since plotting $\ln \mathrm{K}_{\mathrm{ads}}$ against $1 / \mathrm{T}$ gave straight lines, as shown in Fig. (13).

Table 7. Thermodynamic parameters of adsorption of $\mathrm{P}(\mathrm{pPD})$ on MS electrode surface in $1.0 \mathrm{M} \mathrm{HCl}$ solution. Data from polarization technique.

\begin{tabular}{|c|c|c|c|c|}
\hline Temp , (K) & $\mathrm{K}_{\text {ads }} \times 10^{-6}$ & $\Delta \mathrm{G}_{\text {ads }}^{\mathrm{o}}\left(\mathrm{k} \mathrm{J} \mathrm{mol}^{-1}\right)$ & $\Delta \mathrm{H}_{\text {ads }}^{\mathrm{o}}\left(\mathrm{k} \mathrm{J} \mathrm{mol}^{-1}\right)$ & $\Delta \mathrm{S}_{\text {ads }}^{\mathrm{o}}\left(\mathrm{J} \mathrm{mol}^{-1} \mathrm{~K}^{-1}\right)$ \\
\hline 298 & 0.066 & -37.44 & & \\
\hline 303 & 0.053 & -37.52 & -67.34 & -211.27 \\
\hline 308 & 0.045 & -37.72 & & \\
\hline
\end{tabular}

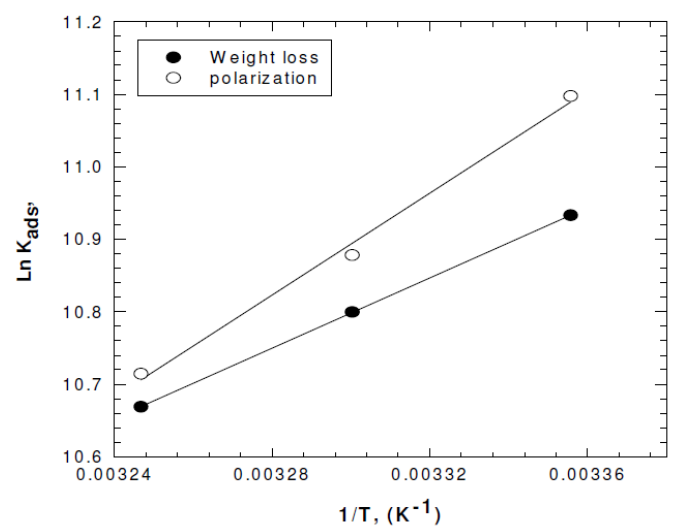

Figure 13. Relation between $\ln \mathrm{K}_{\mathrm{ads}}$ and $1 / \mathrm{T}$ for $\mathrm{MS}$ electrode in $1.0 \mathrm{M} \mathrm{HCl}$.

The calculated values of $\Delta \mathrm{G}^{\mathrm{o}}$ ads,$\Delta \mathrm{H}^{\mathrm{o}}$ ads and $\Delta \mathrm{S}^{\mathrm{o}}$ ads obtained from weight loss and polarization methods are given in Tables (6) and (7), respectively. It seems that the thermodynamic functions of the adsorption process obtained from the two methods are parallel and in a good agreement. The calculated values of $\Delta G_{\text {ads }}^{o}$ 
are low and negative, suggesting that the nature of this inhibitor adsorption is mainly physisorption and spontaneous [22-25]. It is usually accepted that the value of $\Delta \mathrm{G}_{\text {ads }}^{\mathrm{o}}$ around $-20 \mathrm{~kJ} \mathrm{~mol}^{-1}$ or lower indicates the electrostatic interaction between charged metal surface and charged organic inhibitor in the bulk of the solution [26], while those around $-40 \mathrm{~kJ} \mathrm{~mol}^{-1}$ or higher involve charge sharing transfer between the metal surface and the organic inhibitor [27]. The negative values of $\Delta \mathrm{H}^{\mathrm{o}}$ ads indicate that the adsorption is an exothermic process [18]. The magnitude of the values of $\Delta \mathrm{H}^{\mathrm{o}}$ ads and $\Delta \mathrm{S}^{\mathrm{O}}$ ads is characteristic of the occurrence of replacement process during adsorption [28, 29].

\section{Conclusion}

The tested $\mathrm{P}(\mathrm{p}-\mathrm{PD})$ compound inhibits the corrosion of mild steel in $\mathrm{HCl}$ media. The addition of $\mathrm{P}(\mathrm{p}-\mathrm{PD})$ does not change the mechanism of either mild steel dissolution or hydrogen evolution reaction. $\mathrm{P}(\mathrm{p}-\mathrm{PD}$ acts as a mixed type inhibitor, but predominantly as an anodic one. The inhibition efficiency value increases with the inhibitor concentration and decreases by increasing acid concentration and temperature. The corrosion inhibition of $\mathrm{P}(\mathrm{p}-\mathrm{PD}$ can be interpreted by a simple blocked fraction of the electrode surface related to the adsorption of the inhibitor species, according to a Langmuir isotherm on the MS and mainly the adsorption process is spontaneous and exothermic physisorption. The results obtained from polarization curves and the weight loss data are in reasonably good agreement.

\section{References}

1. P. Zhao, Q. Liang, Y. Li, Appl. Surf. Sci. 252 (2005) 1596.

2. A.M.S. Abdennabi, A.I. Abdulhadi, and S. Abu-Orabi, Anti-Corros. Met. Mater. 45 (1998)103.

3. K.F. Khaled, Electrochim. Acta 48 (2003) 2493.

4. K. Emregul, O. Atakol, Chem. Phys. 82 (2003) 188.

5. D.M. Lenz, M. Delamar, C.A. Ferreira, J. Electroanal. Chem. 54 (2003) 35.

6. M. El Azhar, M. Traisnel, B. Mernari, L. Gengembre, F. Bentiss, M. Lagrenee, Appl. Surf. Sci. 185 (2002) 197.

7. $\quad$ M. Ajmal, A.S. Mideen, M.A. Quraishi, Corros. Sci. 36 (1994) 79.

8. S. Arab, E.E.A. Noor, Corrosion 49 (1993) 122.

9. M.A. Quraishi, R. Sardar, Mater. Chem. Phys. 78 (2002) 425.

10. S. Arab, E.E.A. Noor, Corrosion 49 (1993) 122.

11. Z.D. Stankovic, M. Vukovic, Electrochim. Acta 41 (1996) 2529.

12. S.M. Sayyah, M.M. El-Deeb, S.M. Kamal, R.E. Azooz, Appl. Poly. Sci. 117 (2010) 943.

13. S.S. Abd El Rehim, H.H Hassan, M.A. Amin, Mat. Chem. Phys. 78 (2002) 337.

14. M.A. Amin, S.S. Abd El Rehim, E.E.F. El-Sherbini, R.S. Bayoumi, Inter. J. Electrochem. Sci. 3 (2008) 199.

15. M.A. Amin, J. Appl. Electrochem. 36 (2006) 215. 
16. J.O'M. Bockris, A.K.N. Reddy, "Modern Electrochemistry" Vol. 2, Platinum Press, N.Y. 1977.

17. F. Mansfeld, "Corrosion Mechanism" p. 119, Marcel Dakkar, N.Y. 1987.

18. J. March: Advanced Organic Chemistry: 3rd. ed., Will Eastern, New Delhi, 1988.

19. E. McCaaffery, "Corrosion Control by Coating", Science Press, Princeton, 1979.

20. Y. Yan, W. Li, L. Caiand and B. Hou, Electrochim Acta 53 (2008) 5953.

21. I. Langmuir, J. Am. Chem. Soc. 39 (1947) 1848.

22. D. Do, "Adsorption Analysis: Equilibria and Kinetics", Imperial Collage Press, London, 1998.

23. E. Khamis, I. Mellucci, R.M. Lantanision, E.S.H. El-Ashry, Corros. Sci. 47 (1991) 677.

24. F.M. Donahue, k. Noble, J. Electrochem. Soc. 112 (1965) 886.

25. P.W. Atkins, Physical Chemistry, 6th. Ed., Oxford Univ. Press 1999, p857.

26. H. Keles, M. Keles, I. Dehri, O. Serindag, Colloids surf. A: Physicochem. Eng. Aspects 320 (2008)138.

27. A.K. Singh, M.A. Quraishi, Corrosion Sci. 51 (2009) 2752.

28. B.A. Abdel Nabey, E. Khamis, M. Sh. Ramadan, A. El-Gidy, 8th Eur. Symp. Corros. Inhibitors, Ann Univ. Ferrara, NS Sez. 10 (1995) 299.

29. M.J. Lampinen and M. Fomino, J. Electrochem. Soc. 140 (1993) 3537. 